\title{
El discurso de los expertos a propósito de la telerrealidad
}

\author{
María Dolores CÁCERES ZAPATERO \\ Universidad Complutense de Madrid \\ caceres@ccinf.ucm.es
}

Recibido: 2 de abril de 2013

Aceptado: 3 de octubre de 2013

\begin{abstract}
Resumen
Este trabajo presenta el discurso de los expertos en torno a la construcción de sentido a propósito de los programas de telerrealidad y reality shows que constituyen, más que un repertorio de géneros, una tendencia consolidada dentro de la televisión actual. Estos contenidos, muy controvertidos pero apreciados por la audiencia, se caracterizan por el protagonismo de la gente común, exhibición de la intimidad y alto grado de espectacularización. Los objetivos de la investigación han sido explicar cuál es el alcance de estos programas populares, qué imaginario social configuran, cómo vinculan al espectador y cuál es el papel que juega el medio. Se ha utilizado la técnica Delphi que aporta un discurso consensuado basado en las declaraciones y opiniones de expertos provenientes de distintas especialidades relacionadas con el tema.
\end{abstract}

Palabras clave: Telerrealidad, Delphi, aprendizaje social, valores, imaginario social.

\section{The experts' discourse about Reality TV}

\begin{abstract}
This paper presents the experts' discourse about the process of meaning-construction around Reality TV and reality shows. They are much more than a genres' repertoire, as they constitute a solid trend in current TV. These contents are very controversial but they are also appreciated by the audience; they are characterized by the salience attributed to common people, an exhibition of their privacy and a high degree of spectacularization. The purposes of this research were to explain which is the scope of these popular programs, which social imaginary are they building up, how they can get the viewers involved and which is the role played by the medium. A Delphi study was completed in order to capture a consensual discourse based on the opinions of experts coming from diverse disciplines related to the topic.
\end{abstract}

Keywords: Reality TV, Delphi, social learning, values, social imaginary.

\section{Referencia normalizada}

CÁCERES ZAPATERO, María Dolores (2014): "El discurso de los expertos a propósito de la telerrealidad". Estudios sobre el Mensaje Periodístico. Vol. 20, Núm. 2 (julio-diciembre), págs.: 661-676. Madrid, Servicio de Publicaciones de la Universidad Complutense.

Sumario: 1. Introducción. 2. Objetivos y metodología. 3. Resultados; 3.1. La vinculación con el espectador; 3.1.1. Motivaciones e implicación del receptor en los programas de telerrealidad; 3.1.2. Participación y fruición ante los programas de telerrealidad; 3.2. Telerrealidad y aprendizaje social; 3.2.1. El efecto aprendizaje social del espectáculo televisivo; 3.2.2. El imaginario social que construye la televisión; 3.3. El papel que juega el medio. 4. Conclusiones y discusión; 4.1. El aire de un tiempo; 4.2. Aprendizaje social; 4.3. Deslegitimación simbólica; 4.4. La revalorización de la cultura cotidiana; 4.5. La ficcionalización del reality. 5 . Referencias bibliográficas.

\section{Introducción}

El análisis de reality shows ha sido un tema ampliamente abordado en la literatura sobre comunicación de los últimos años por lo novedosos y controvertidos que fueron desde el momento de su aparición, por la progresiva y rápida implantación en todas las televisiones y por el éxito de audiencia que han supuesto. Hoy perviven con 
fuerza en sus distintas derivas y reformulaciones posteriores, dando lugar a una voluminosa producción difícil de sintetizar.

Se han hecho numerosos trabajos de marcado carácter crítico, centrados principalmente en la función de entretenimiento (Lacalle, 2001), los valores, la estructura y la reflexión ética (León, 2009, Camps, 2008, Bouza, 2000), sobre todo a partir de análisis de contenido o análisis textuales de programas concretos (Sampedro, 2002, Lacalle, 2000, Cebrián, 2003, Cáceres, 2001, 2002). Se han abordado las nuevas narrativas de la telerrealidad (González Requena, 2010, Torregrosa, 2010), taxonomías y formatos (Cebrián, 1998), así como aspectos históricos y genealogía del género (Palacio, 2007) o, a un nivel macro, los procesos de mediación (Cáceres, 2010) y la construcción del imaginario colectivo a partir de la transformación de la realidad en espectáculo (Imbert, 2003, 2008). Sin embargo, salvo algunas excepciones como el trabajo de Aierbe, Medrano y Martínez de Morentín (2010) que indaga sectorialmente en cómo los adolescentes pueden extraer elementos de aprendizaje para afrontar situaciones interpersonales y tomar conciencia de problemas sociales relevantes, escasean otras perspectivas de tipo cualitativo abordadas desde técnicas observacionales o conversacionales y más aún desde la recepción y su contexto (Lamuedra, 2005, Castañares, 2006).

Esta investigación aporta el discurso de los especialistas en torno a la construcción de sentido a propósito de un conjunto amplio de programas que hoy se han dado en llamar telerrealidad y reality shows y que constituyen, más que un repertorio de géneros, una tendencia dentro de la Neotelevisión. Se presenta un discurso consensuado, basado en las declaraciones y opiniones de expertos provenientes de distintas especialidades relacionadas con el tema, a la hora de explicar cuál es el alcance de estos contenidos populares, qué imaginario social configuran, cómo vinculan al espectador y cuál es el papel del medio.

\section{Objetivos y metodología}

Este trabajo integra en una visión conjunta basada en la voz de los expertos, las distintas vertientes de un tema complejo que tiene implicaciones de carácter psicológico, sociológico, de interpretación individual y apropiación personal de los contenidos mediáticos, y de usos y hábitos de consumo frente a la televisión. Para ello, se ha optado una metodología cualitativa, en concreto por la técnica Delphi, que permite obtener un discurso construido conjuntamente por expertos en el tema, evitando las distorsiones producidas en las discusiones de grupos, como las influencias de unos sujetos sobre otros o los efectos de la adhesión a la opinión mayoritaria (Gaitán y Piñuel, 1998). Esto ha permitido llegar a acuerdos relativos sobre los temas planteados a partir de aproximaciones sucesivas y minimizando los efectos de la interacción, sin sacrificar opiniones importantes e información esencial.

A tales efectos, se confeccionó un cuestionario con objeto recabar opiniones autorizadas de expertos de distintas especialidades (Sociología, Psicología, Educación, Semiótica y Teoría y Medios de comunicación) acerca del discurso de los programas de telerrealidad, acerca de las motivaciones y expectativas de la audiencia ante ellos y acerca del aprendizaje social que pueden/no estar transmitiendo, en la medida en que 
muestran la vida cotidiana de personas reales con las que los receptores pueden fácilmente identificarse.

Los objetivos del Delphi se han centrado en tres ejes temáticos principales que han sido abordados en dos rondas sucesivas, a partir de una decena de preguntas en cada una de ellas. Con este sistema de preguntas y re-preguntas, ha sido posible clarificar y decantar las posturas de los expertos respecto a:

Eje 1: Cómo conectan los programas de telerrealidad con la audiencia y cómo puede explicarse el gusto por su consumo y/o participación en ellos.

Eje 2: Cuál es el aprendizaje social que pueden estar transmitiendo y qué imaginario social ayudan a conformar.

Eje 3: Cuál es el papel que el medio televisión eventualmente puede estar jugando.

La muestra de expertos ha estado constituida por catorce especialistas ${ }^{1}$ provenientes de distintas disciplinas que suponen voces autorizadas a la hora de opinar sobre la virtualidad de los discursos sociales.

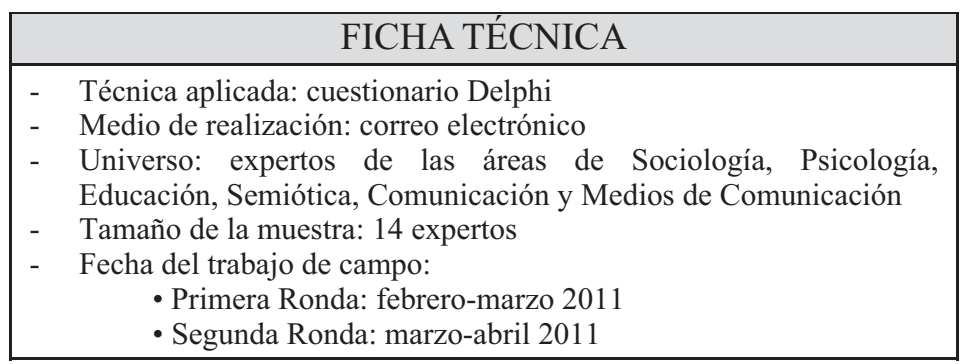

\section{Resultados}

\subsection{La vinculación con el espectador}

De todos es sabido que estos programas gozan de gran aceptación por parte de un sector amplio de telespectadores como muestran los datos de audiencia. Se trataba de reflexionar a propósito de los mecanismos mediante los cuales estos programas vinculan al receptor. Esta cuestión fue abordada a partir de tres preguntas formuladas en la primera ronda del Delphi:

1) En su opinión, ¿por qué a la gente le gusta ver estos programas?

2) ¿Qué relevancia tiene el hecho de que los programas de telerrealidad muestren situaciones de la vida cotidiana, conocidas por todos, en las que es fácil reconocerse por parte de los telespectadores?

3) ¿Cuál de estos factores cree que prima a la hora de explicar el éxito de estos programas: 1) resultan interesantes para la audiencia porque son intrascendentes y permiten pasar el rato sin pensar; 2) satisfacen la curiosidad por las vidas aje-

${ }^{1}$ Los expertos que han colaborado en este trabajo han sido: Agustín García Matilla, Alejandra Walzer, Alejandro Perales, Charo Lacalle, Concepción Medrano, Fermín Bouza, Gérard Imbert, Inmaculada Ríus, Isabel Larraburu, José Carlos Rueda, José Luís Piñuel, Mariano Cebrián, Miguel Ángel Ortiz y Wenceslao Castañares. Desde estas páginas se agradece encarecidamente la generosa contribución de todos ellos que con su valiosa aportación han hecho posible este trabajo. 
nas; 3) permiten al receptor extraer algún tipo de aprendizaje sobre sí mismos y sobre los demás?

\subsubsection{Motivaciones e implicación del receptor en los programas de telerrealidad} A la pregunta de por qué a la gente le gusta ver estos programas, los expertos apuntaron distintas y variadas motivaciones en función de los contenidos concretos de que se trate en cada caso. La respuesta más frecuentada fue que detrás del gusto por estos programas hay mecanismos diversos de proyección e identificación con sus protagonistas y situaciones reconocibles de la vida cotidiana. Estos mecanismos servirían para proveerse de recursos sociales a la hora de afrontar su propia vida, alimentar el sueño de que la gente sencilla también puede ser protagonista en televisión, que podrían tener un efecto de catarsis e, incluso, hacer que el telespectador se posicione a favor o en contra de los protagonistas de la situación mostrada.

También se apuntaron, con bastante énfasis, motivaciones en otros sentidos: por ejemplo, el hecho de que proporcionan entretenimiento fácil que permite evadirse y no requiere esfuerzo, ni plantea retos complejos o inalcanzables. Cuatro expertos opinaron que conectan con lo oculto, lo excepcional, el voyeurismo y exhibicionismo. Otros expertos aportaron aspectos relacionados con una función de integración social, por ejemplo que suponen un medio para entrar en relación con los otros, conversando, manifestando puntos de vista o compitiendo en conocimientos, e incluso pueden compensan de la falta de sentido de comunidad, perdido en nuestra época.

Por último, algunos expertos opinaron que se relaciona con el hecho de que estos programas combinan elementos muy primarios presentes también en otros relatos, como emociones, sentimientos, conflictos, sexo, venganza. Fue minoritaria la opinión de que conectan con una aspiración de éxito y dinero fácil y sin esfuerzo.

Tres expertos mencionaron el papel que cumple el medio para fidelizar a la audiencia a través de estrategias comunicativas de vinculación como la serialización, el atractivo de los protagonistas o el hábito que procede de la sobreexposición a una oferta muy consolidada en las parrillas. Este aspecto que se relaciona con el papel que puede jugar la televisión como medio y sus estrategias, fue retomado de nuevo en la segunda ronda a partir de tres nuevas preguntas.

A la segunda pregunta a propósito de la relevancia que tiene el hecho de que los programas de telerrealidad muestren situaciones de la vida cotidiana conocidas por todos en las que es fácil reconocerse por parte de los telespectadores, las respuestas apuntaron en distintas direcciones. La mayoría de los expertos opinó que es relevante o muy relevante tanto para la cadena como para el espectador que puede ver reforzada su condición social y cultural e incorporar conductas y conocimientos a su vida particular.

Solo tres expertos consideraron que no es relevante porque los espectadores no se reconocen en un espectáculo televisivo que, sin embargo, sirve para restaurar el sentido de comunidad perdido. Por último, un experto consideró que es ambivalente: proporcionan reconocimiento pero también evasión y elementos de sorpresa.

A la tercera cuestión a propósito de qué factores priman a la hora de explicar el éxito de estos programas, lo primero que cabe señalar es la complejidad de dar una res- 
puesta unitaria por la diversidad de espectadores y sus características diferenciales. No obstante, la mayoría de los expertos, nueve, coincidieron en que estos programas satisfacen principalmente la curiosidad por las vidas ajenas y, secundariamente, permiten pasar el tiempo de forma intrascendente y proporcionar aprendizaje social.

Frecuentemente se critica estos programas por su falta de calidad y por ser poco edificantes. Se trataba de reflexionar a propósito de los valores sociales, o en su caso contravalores, presentes en los programas de telerrealidad como un elemento más de vinculación con el espectador. Esta cuestión se trabajó a partir de otras tres preguntas:

1) En su opinión, ¿cuáles son los principales valores y/o contravalores que presentan estos programas?

2) En su opinión, ¿estos programas fomentan el morbo y el gusto por lo extremo?

3) ¿Cómo valora el tratamiento que reciben las personas y experiencias de vida que se relatan en los programas de telerrealidad y reality shows?

A la primera pregunta a propósito de los principales valores y/o contravalores que presentan estos programas, la mayor parte de los expertos señaló que transmiten contravalores antes que valores. Así mencionaron un número elevado de ellos que apuntan en distintas direcciones: trivialidad, inanidad, frivolidad, un modelo de vida basado en el desmerecimiento del esfuerzo y la aplicación de la conocida fórmula "todo vale", egoísmo, encono, violencia, chabacanería, deslealtad, agresividad, interés, competitividad, machismo, insolidaridad, publicitación de la privacidad. También se señalaron otros que apuntan a dos aspectos que se relacionan con el medio televisión: el primero, la vejación y humillación a la que en ocasiones se somete a los participantes en los programas televisivos por parte de las cadenas; el segundo, intrusismo en la profesión periodística que es ejercida a veces por diletantes.

Si bien las respuestas mayoritarias se inclinan rotundamente hacia el lado de los contravalores, también hay que señalar que se mencionaron por parte de dos expertos algunos valores: compañerismo en escasas ocasiones, valores de rango comunitario y una función didáctica que a veces se puede desprender de determinados formatos. No se puede olvidar que todo el repertorio amplísimo de programas que hemos englobado bajo el rótulo de telerrealidad responden a variados formatos y temáticas que van desde los denominados tele-encierros al formato coach.

De todos es sabido, que frecuentemente estos formatos presentan situaciones extremas, escabrosas o infrecuentes. A partir de la segunda pregunta, los expertos fueron invitados a pronunciarse a propósito de si estos programas fomentan el morbo y el gusto por lo extremo. La mayoría de los expertos entienden que fomentan ambos pero sobre todo el morbo, a veces como consecuencia de la sobre-exposición a estos contenidos, sin olvidar que en otros casos, la habituación lo mitiga. Respecto al gusto por lo extremo, se señaló que estas situaciones no obstante, se suelen cuidar y dosificar para mantener vivo el interés del público y además quedan siempre circunscritas a las reglas de un juego narrativo y discursivo que el emisor controla. En última instancia, se señala, ambos siempre han formado parte de las relaciones interpersonales cuando éstas son trágicas o ejemplares. Dos expertos se pronunciaron en el sentido opuesto, puede ocurrir que produzcan rechazo y regresión sociológica a la comunidad. 
La valoración que los expertos hacen del trato que reciben las personas y sus experiencias cotidianas es claramente negativa aunque con muchos matices. Se apunta el trato ofensivo o vejatorio hacia las personas, que es aceptado por una búsqueda de compensación económica o de fama y promoción personal. En otros casos, se habla claramente de manipulación por parte de las cadenas de televisión que incluso llegan al engaño y a la presión psicológica para que esas personas revelen intimidades con el fin de explotar su intimidad y universo emocional.

Por otra parte, se señaló que el trato recibido por los personajes que aparecen en la televisión no siempre es igual, que depende de los formatos y del tipo de personaje en cada caso: a veces más condescendiente cuando se trata de famosos y más denigrante sin embargo, cuando se trata de personas menos conocidas.

\subsubsection{Participación y fruición ante los programas de telerrealidad}

Los programas de telerrealidad y reality shows muestran frecuentemente la intimidad de las personas como ya han apuntado algunos expertos y a veces situaciones extremas como se ha dicho. Se trataba de reflexionar a propósito de las motivaciones y actitudes que pueden llevar a los telespectadores a la participación y consumo de estos programas. Estas cuestiones se abordaron a partir de cuatro preguntas:

1) ¿El afán por exhibir la propia intimidad ante los otros se relaciona, en su opinión, con una forma de narcisismo, con la búsqueda de fama y notoriedad o con la necesidad de reconocimiento ajeno? ¿Señalaría otra explicación?

2) ¿El gusto por contemplar la intimidad ajena se relaciona, en su opinión, con la búsqueda del vínculo social y/o combatir la soledad y el individualismo en la sociedad actual? ¿Qué otra explicación aduciría?

3) ¿Cómo explicaría la fruición del público en la contemplación del sufrimiento ajeno en distinto grado?

4) ¿Cómo explicaría la participación de algunas personas en programas o concursos de telerrealidad en donde son sometidos a situaciones extremas (cansancio, estrés, dolor, humillación, etc.)?

Muchos de esos programas se basan en mostrar, a veces de forma muy explícita, las intimidades de la gente común o de personas conocidas. Se trataba de profundizar, a partir de las dos primeras preguntas formuladas a los expertos, en cómo se relaciona este aspecto con la audiencia, tanto desde el punto de vista de la fruición en la exhibición de la propia intimidad como desde el gusto por contemplar la ajena.

La mayoría de los expertos coincidieron en que la exhibición pública de la intimidad se relaciona con una forma de narcisismo, con la búsqueda de fama y notoriedad y con la necesidad de reconocimiento ajeno. Cuatro expertos, matizaron que detrás de la búsqueda de fama, notoriedad, reconocimiento ajeno y necesidad de hacerse visible ante los demás, se detectan los rasgos narcisistas que caracterizan a nuestra sociedad contemporánea. Un tercio de la muestra de expertos señaló además que son razones de tipo económico las que frecuentemente se ocultan detrás de las anteriores e, incluso, podrían satisfacer necesidades sexuales. Dos expertos apuntaron en otra dirección y es que la intimidad hecha pública en la televisión se relaciona con la falta 
de comunicación y con elementos de regresión comunitaria. Todo ello sin olvidar el hecho importante de que, en última instancia, hay factores diferenciales de tipo individual muy difíciles de evaluar.

Respecto al gusto por contemplar la intimidad ajena que puede guiar la exposición del receptor a la televisión, un tercio de los expertos ratificó las hipótesis propuestas y lo relaciona con una búsqueda de vínculo social y con combatir la soledad, el aislamiento y el individualismo. Un segundo tercio de la muestra opinó que el gusto por las vidas ajenas ha existido siempre, que puede provenir del sentimiento de vacío ante la propia y que además la fruición proviene de la posición en que se coloca el espectador-observador: por encima del observado.

Además se señalaron otros motivos que se relacionan con algunas formas de aprendizaje de aspectos prácticos de la vida cotidiana y resolución de los propios conflictos, alimentando el mito de que la transparencia permite conocer el verdadero sentido de la vida, en este caso de sujetos comunes similares al espectador. Se añadieron también otros matices de proyección e identificación del sujeto que puede experimentar, por ejemplo, admiración hacia aquellos que en pantalla hacen lo que el mismo desearía hacer. Por último, un experto expresó que es el medio, a partir de mecanismos de fidelización, el que provoca esta adicción a lo ajeno.

Otro aspecto que a menudo aparece en algunos formatos de telerrealidad, como por ejemplo en concursos, es el sufrimiento en distinto grado y modalidad. Los expertos fueron preguntados por la fruición que el receptor puede encontrar en la contemplación de estos contenidos y por la participación en ellos. Lo primero que hay que destacar es la complejidad que tiene dar respuesta a una cuestión de este calado, lo que se reflejó en las matizaciones aportadas por los expertos.

Principalmente, se aducen por la mayoría de los consultados razones que se relacionan con el hecho de que el dolor propio y ajeno es algo que siempre ha estado presente en la historia de la humanidad bajo distintas expresiones y que supone una experiencia catártica. Otras respuestas hablan de una relación ambivalente de identificación y distanciamiento, de necesidad de hacer daño al otro y también de solidarizarse con él; otras opiniones hablan de conductas perversas, de que ver el dolor ajeno compensa del propio y de la gratificación psicológica en la posición de superioridad en la que puede colocarse el espectador. También se apunta el sentido de comunidad que puede proporcionar.

También se añadieron otras consideraciones relacionadas con la percepción del sentir que tiene el sujeto contemporáneo. Actualmente, se señala, se han abolido las fronteras entre el sentir positivo (emociones) y el sentir negativo (violencia) en una sociedad sobre-estimulada en la que se hace necesario ir cada vez más lejos para mantener e incentivar el interés por lo que el medio ha convertido en mero espectáculo lúdico.

Por último a la pregunta sobre las motivaciones que podrían guiar a la audiencia a participar en un programa de telerrealidad, las respuestas apuntaron en tres direcciones. La primera de ellas es la búsqueda y afán de notoriedad; la segunda, los intereses económicos que pueden compensar de las penalidades sufridas. La tercera dirección apunta a factores de tipo psicológico: actitudes narcisistas y exhibicionistas, psicopatología, competición en la que se puede ganar, experimentar los propios lími- 
tes y buscar nuevas experiencias, compensar la falta de sentido en la vida cotidiana propia y catarsis.

\subsection{Telerrealidad y aprendizaje social}

Las respuestas de los expertos a las preguntas de la primera ronda apuntaban a que los contenidos de telerrealidad proporcionan elementos de aprendizaje social que el telespectador incorpora a la hora de gestionar su propia vida y que el éxito de estos programas radica en que satisfacen la curiosidad por las vidas ajenas y nos devuelven a lo comunitario. Se trataba ahora de profundizar en estas cuestiones con más detalle, lo que se llevó a cabo a partir de tres preguntas:

1) ¿Qué efectos puede tener el hecho de que estos programas proporcionen elementos de aprendizaje social en forma de espectáculo televisivo?

2) ¿Corrobora que el éxito de estos programas puede explicarse sobre todo porque conectan con algo que siempre ha estado presente históricamente como es la curiosidad por las vidas ajenas?

3) ¿La fruición escópica de la intimidad ajena se puede entender como un mecanismo de sublimación de la necesidad de vínculo social?

\subsubsection{El efecto aprendizaje social del espectáculo televisivo}

Se asume que hoy está superada la noción clásica que explica los efectos de los medios en términos mecanicistas, y que más bien se trata de dar cuenta de los procesos de influencia en términos de distintas apropiaciones que llevan a cabo los receptores frente a los contenidos de dichos medios. De ahí, que se haya optado por la técnica Delphi que permite recabar opiniones y apreciaciones diversas provenientes de varios horizontes disciplinarios, que pueden aportar diferentes explicaciones y matices a la complejidad de la conducta humana.

Se trataba de someter a la consideración de los expertos si se puede hablar de aprendizaje social y en qué términos, toda vez que estos programas se caracterizan, por una parte, por un alto grado espectacularización, y por otra, porque sus protagonistas, las más de las veces, son sujetos comunes con los que la audiencia puede fácilmente identificarse. Las respuestas de los expertos a propósito de cuál puede ser la relevancia de aquellos elementos de aprendizaje que el receptor extrae de su exposición a los contenidos de telerrealidad, apuntaron en distintas direcciones.

En primer lugar, hay que destacar el acuerdo mayoritario (nueve del total de los expertos) en que sí proporcionan elementos de aprendizaje social. No obstante, este aprendizaje no es homogéneo dada la variabilidad individual y la credibilidad que en cada caso otorgue el receptor al mensaje.

Los expertos señalaron que este aprendizaje consiste en legitimar o deslegitimar conductas exhibidas por los héroes de la vida cotidiana, lo que puede resultar en normalizar comportamientos y actitudes que pueden calificarse de antisociales y que, si bien sirven para captar la atención del televidente, pueden entrar en contradicción con los valores que la familia o instituciones educativas quieren transmitir. Los expertos hablaron de contramodelos de conducta y relaciones sociales, de ausencia de valores (por ejemplo, dignidad), de generalización de comportamientos anómicos con los que 
el espectador se podría identificar y después imitar e, incluso, de estigmatizar algunas conductas que aún siendo propias, no se reconocen como tales. Es decir, estaríamos ante el efecto Tercera Persona que explica la atribución a terceros de aquello que el sujeto no se reconoce a sí mismo.

Un tercio de la muestra de expertos planteó que estos programas pueden desrealizar la relación con las cuestiones sociales, derivando en juego o banalización cualquier aspecto de la realidad social. El tomo hilarante a veces esgrimido y la ficcionalización de la realidad podrían, en suma, distorsionarla. Un experto señaló también que podría disminuir la valoración de los periodistas como colectivo, al ser frecuentemente identificados con los conductores de los programas.

Solo dos expertos señalaron que no hay aprendizaje social o que éste puede ser el mismo que el que se cabe extraer de cualquier otro contenido televisivo. Quizá estos programas son contemplados solo como un espectáculo y no como una ventana abierta a las vidas ajenas.

A la cuestión de si se corrobora que el éxito de estos programas puede explicarse sobre todo porque conectan con algo que siempre ha estado presente históricamente como es la curiosidad por las vidas ajenas, la respuesta afirmativa fue unánime, añadiendo la puntualización de que fomentan el voyerismo que siempre ha existido en todas las comunidades. Otros matices interesantes relacionan la cuestión anterior con el modelo social actual carente de valores y con el hecho de que contemplar los problemas y conflictos de las vidas ajenas puede ayudar a sobrellevar los propios, aunque a veces estos programas se sitúen en esa línea difícil de trazar que separa el morbo del interés humano. Según otra vía diferente de explicación, conectarían con la necesidad de identificación con los personajes de la televisión para construirse una identidad que resulte atractiva en la vida real. También se apuntó que el éxito puede provenir de los factores de fidelización que añade el medio, como el suspense o crear expectación.

Preguntados los expertos acerca de la fruición escópica del espectador en la intimidad ajena como mecanismo de sublimación de la necesidad del vínculo social perdido en nuestras sociedades actuales, las respuestas se reparten, casi de manera uniforme, entre aquellos que piensan que no por la variabilidad individual, aquellos que piensan que en parte sí y los que se posicionan afirmativamente por el relativo fracaso de la relación social y la búsqueda de vínculo comunitario.

\subsubsection{El imaginario social que construye la televisión}

La mayor parte de los expertos consultados en la primera ronda de este Delphi declararon que los programas de telerrealidad presentan principalmente contravalores (trivialidad, inanidad, desmerecimiento del esfuerzo, egoísmo, violencia, encono, machismo) y escasamente algún valor (capacidad de actuar en público, compañerismo, aguante o valores de rango comunitario). Habida cuenta de que la televisión muestra el mundo, lo que hacen las personas, cómo se relacionan y qué valores son más apreciados, se trataba de profundizar en el imaginario, es decir aquello que da sentido a las prácticas sociales (Taylor, 2006), que estos programas pueden estar configurando. Esto se hizo a través de tres preguntas: 
1) ¿Qué relevancia puede tener, en su opinión, el hecho de que la televisión preste la misma atención y otorgue el mismo nivel (es decir con el mismo tratamiento) a personajes famosos y a personas de la vida pública, a cuestiones importantes y a otras intrascendentes?

2) ¿La publicitación de la privacidad en los programas de telerrealidad, supone, en su opinión, una revalorización de la cultura cotidiana o más bien es el resultado de la lógica económica de la televisión de hacer rentables todos sus productos a cualquier precio?

3) ¿El afán de fama y notoriedad que lleva a sujetos comunes a participar en programas de telerrealidad es, en su opinión, una nueva versión de esta aspiración histórica presente en los relatos épicos, o se trata de algo distinto? ¿En qué radica la diferencia si es que la hay, en su opinión?

La mayoría de los expertos consultados respondió a la primera de estas preguntas que banalización y pérdida de referentes así como fomentar la falta de interés por los asuntos públicos. Detrás de esta práctica mediática estaría la lógica de mercado que rige el funcionamiento de la televisión a la que se supeditan otras decisiones respecto a los contenidos y su tratamiento.

Respecto a la segunda pregunta, la mayoría de los expertos se posicionaron a favor de la segunda opción presentada. La televisión perseguiría rentabilizar formatos baratos con la connivencia de la audiencia que se encuentra cómoda en esta tendencia que se calificó de intimista y que, en opinión de un experto, supone una revancha de lo microscópico sobre lo macroscópico. Dos de los expertos consultados respondieron que ambas cosas se dan y un experto consideró que efectivamente sí supone una revalorización de la cultura cotidiana.

Respecto a la tercera pregunta los expertos opinaron mayoritariamente que detrás de la búsqueda de fama y notoriedad se esconde un interés de carácter económico y solo secundariamente otro tipo de razones; entre ellas, tendencias narcisistas y esos minutos de gloria de los que hablaba Andy Warhol. En otros casos, se pueden encontrar compensaciones de tipo psicológico como obtener el perdón por acciones cometidas o incluso denunciar injusticias. Respecto a la cuestión de si es posible encontrar en las hazañas cotidianas de los sujetos comunes una nueva versión de los relatos épicos, se encontraron respuestas tanto en sentido afirmativo como negativo.

\subsection{El papel que juega el medio}

En la primera ronda de este Delphi se mencionó el protagonismo que puede tener la televisión a la hora de conformar el gusto por los contenidos de telerrealidad. Las apreciaciones y respuestas de los expertos mostraron que las estrategias mediáticas (fidelización, habituación por sobre-exposición, serialización, alimentar la adhesión a estos contenidos) son un factor a tener en cuenta a la hora de explicar este gusto de los espectadores por los programas de telerrealidad. Se trataba, en la segunda ronda, de profundizar en el papel que juega la televisión como medio que despliega determinadas estrategias comunicativas para captar y retener a la audiencia. Esto se llevó a cabo a partir de estas tres preguntas: 
1) ¿Aceptando que el cliente de la televisión no es el espectador sino el anunciante y que el telespectador es producido por la televisión, en su opinión, qué tipo de persona puede estar produciendo la industria de la televisión con este tipo de programas?

2) ¿Está de acuerdo con que la industria mediática banaliza cualquier experiencia vital convirtiéndola en un producto de consumo al servicio de intereses económicos, o se puede decir que estos programas también han aportado creatividad y entretenimiento a la televisión?

3) En su opinión, ¿antepone la televisión sus intereses económicos a cualquier tipo de consideración ética?

Las respuestas a la primera cuestión planteada se orientaron mayoritariamente hacia dos líneas de explicación. Por una parte, el reconocimiento de que la conformación de la persona no es solo el resultado de la acción de la televisión, sino de una suma compleja de factores y que, por consiguiente, no se puede establecer en términos deterministas. Hoy se sabe que el receptor no es siempre un sujeto pasivo que acepta las lecturas propuestas por el emisor, sino que se hacen distintas interpretaciones en función de las características e historia personal del sujeto y sus rasgos de identidad. Por otra parte, se señaló que los valores y visiones propuestas, pueden estar conformando sujetos principalmente conformistas y adaptados al sistema. Dado que el receptor es omnívoro, se ha dicho, y que estos contenidos son fáciles de consumir y halagan y gratifican al espectador, se puede fomentar una postura pasiva y poco crítica, mal gusto y pérdida de algunos valores, entre ellos, la dignidad a juicio de algunos expertos consultados.

Respecto a la segunda cuestión relativa a la aportación del medio y los intereses económicos que subyacen a las estrategias comunicativas de la televisión, ambas hipótesis planteadas se corroboraron. Por una parte, algunos expertos señalaron que detrás de los contenidos de telerrealidad hay razones económicas más que elementos de creatividad. Es sabido que este tipo de programas se caracterizan por bajos costes de producción, lo que los convierte en formatos atractivos para las cadenas por el escaso riesgo que entrañan estas fórmulas baratas que han sido ya ensayadas y probada su aceptación por parte de la audiencia. En esta línea de explicación, algunos expertos señalaron que, en origen, este tipo de formatos sí supusieron una transformación del entretenimiento con elementos de innovación y creatividad, pero que en el momento actual hay que hablar de reiteración e hibridismo de formatos ya gastados. Por otra parte, se señaló que principalmente aportan mero entretenimiento más que creatividad y muchos de ellos altas dosis de banalización de la experiencia humana.

Respecto a la última cuestión planteada a propósito de si la televisión antepone sus intereses económicos a cualquier tipo de consideración ética, la respuesta casi unánime fue afirmativa, solo un experto se pronunció en sentido negativo. Sí se apuntó como elemento diferencial la televisión pública, a la que se le reconoce la observancia de consideraciones éticas por encima del beneficio económico. 


\section{Conclusiones y discusión}

La primera conclusión que cabe señalar es que se trata de un fenómeno complejo que presenta numerosos matices difíciles de sintetizar en conclusiones unitarias, por: 1) la variabilidad de los sujetos individuales, y 2) la variabilidad de un programa a otro.

Plantearse el alcance de los programas de telerrealidad y el aprendizaje social que puede extraer la audiencia, obliga siempre a tener en cuenta que hay factores diferenciales de índole individual difíciles de evaluar y que solo pueden ser verificados a través de técnicas cualitativas que den la palabra al receptor, lo cual no ha sido abordado en este trabajo. Por otra parte, se hace necesario tener en cuenta que bajo el epígrafe general de telerrealidad se contempla un repertorio amplio de programas y formatos de muy distinta factura, contenido y calidad. En consecuencia, no ha sido fácil encontrar afirmaciones categóricas u homogeneidad completa en las respuestas de los expertos a cuestiones que tienen un hondo calado. No obstante y teniendo siempre presente esta variabilidad en la interpretación individual que puede realizar el receptor, sí se han encontrado acuerdos mayoritarios en las respuestas en torno a distintas líneas que permiten extraer conclusiones. Las matizaciones y la dispersión de alguno de estos datos, son precisamente el reflejo de esta complejidad y la evidencia de que unos aspectos no excluyen otros, más bien conviven y se complementan en distinto grado.

\subsection{El aire de un tiempo}

Respecto al primer eje planteado, en opinión mayoritaria de los expertos, la telerrealidad conecta con la audiencia a través de procesos de proyección e identificación (Cáceres, 2010), facilitados por el hecho de que estos contenidos televisivos muestran principalmente situaciones comunes en las que es fácil mirarse y reconocerse lo que, sin duda, tiene un gran poder de vinculación que puede resultar relevante para el receptor al ver reforzada su condición social y cultural.

Preguntarse por qué triunfan en la sociedad actual este tipo de programas no es una cuestión menor que sin duda remite al aire de un tiempo. Las respuestas de los expertos consultados han indicado que estos programas proporcionan entretenimiento fácil, evasión y diversión, alimentan el voyerismo y exhibicionismo y compensan de la falta de sentido de comunidad. En la era de la imagen y lo visual, en donde lo impactante ha sustituido muchas veces a lo esencial, el espectáculo de la cotidianidad de la experiencia humana televisada parece proporcionar un plus de emoción que da sentido a una existencia que solo merece ser vivida intensamente. En este sentido podría explicarse el gusto por las experiencias extremas (también en otros órdenes de la vida, como los deportes de alto riesgo) y las emociones fuertes, no necesariamente intensas, incluso por el riesgo y la exploración de los límites de la vida y de la muerte. Todos los días saltan a las pantallas ejemplos de situaciones extremas que, bajo la coartada de retos físicos o psíquicos, muestran los límites de la resistencia humana ante el sufrimiento físico (no hace mucho supimos de un programa de televisión que mostró el caso de un concursante que batió los récords de resistencia dentro de una sauna a $110^{\circ}$ grados) o la humillación. Por ejemplo, el reality francés Dilemme ponía en juego un premio de 300.000 euros para el concursante que superara la prueba de con- 
vertirse en mascota del otro equipo durante un día, para lo cual colocaban una bonita correa alrededor del cuello y después tenía que comer y beber de un comedero. Sin embargo, no puede afirmarse que el interés de una parte del público por ver a alguien resistir hasta el límite o verificar la fortaleza humana ante el dolor, se relacione necesariamente con formas de psicopatía o sadismo colectivo. Aunque detrás haya explicaciones psicológicas y ambientales profundas, es posible que el receptor no llegue siempre a percibirlo como sufrimiento o dolor, ya sea por desensibilización o reiteración en las pantallas. Como ha sido apuntado por los expertos, puede relacionarse con una experiencia catártica ante lo que puede ser contemplado como un juego, espectáculo lúdico o mero entretenimiento sin trascendencia.

Los expertos consultados coincidieron en la búsqueda de fama y notoriedad que puede guiar la participación en estos programas como expresión del narcisismo contemporáneo y como vía de acceso a una compensación económica. Exhibicionismo y voyerismo se muestran como los dos polos sobre los que se sustenta la necesidad de reconocimiento ajeno, incluso por encima del respeto a uno mismo, se ha dicho en este estudio. La necesidad de ver y ser visto, de publicitar la propia vida en las pantallas o de contemplar la ajena, se ha trasladado también las redes sociales. Podría decirse que el interés se ha desplazado de la realidad a la narración de la realidad, de la experiencia a su puesta en escena. Las prácticas de los jóvenes en dichas redes (asistir a una fiesta o evento para luego colgarlo en el muro) parecen mostrar este afán por mostrarse y representarse continuamente. En opinión de algunos expertos, esta fama efímera fomenta la vanidad, que no la autoestima.

Según las apreciaciones de los expertos consultados, la telerrealidad conecta con el hiperindividualismo contemporáneo heredero de la disolución de los órdenes colectivos tradicionales (familiares, vecinales, grupales), ofreciendo la oportunidad de indagar en las vidas ajenas y la experiencia vicaria de vínculo social. En este sentido, las redes sociales parecen estar actualmente tomando el relevo a los realities televisivos, brindando la oportunidad de una intimidad compartida en las pantallas que nos devuelve a lo comunitario (la aldea global).

\subsection{Aprendizaje social}

Respecto a si existe aprendizaje social, los expertos se pronunciaron mayoritariamente en sentido positivo aunque, como ya se ha dicho, éste no es homogéneo y difícil de evaluar por la variabilidad individual de los sujetos. No obstante, se han encontrado acuerdos mayoritarios en torno al hecho de que estos contenidos televisivos contribuyen a legitimar y deslegitimar conductas sociales y normalizar comportamientos a partir de modelos y contramodelos y, principalmente, contravalores. Cosa distinta es afirmar a partir de esta conclusión general, que todos los receptores hacen la misma apropiación de esos contenidos. Dicho en otros términos, no se puede establecer en términos directos o de causa-efecto que propuesta una determinada información, todos los receptores hagan la misma interpretación porque, como es sabido, aquí entran en juego toda una serie amplia de factores que tienen que ver con las características identitarias, sociales, psicológicas y de historia personal de los sujetos. Lo cual no minimiza su alcance, sino que lo matiza y señala la complejidad del fenómeno. 
Los escasos expertos que opinaron que no hay aprendizaje social, basan su argumentación en que los contenidos de telerrealidad no son distintos de otros y que se contemplan, simplemente, como un espectáculo que no tiene trascendencia. Aceptar este supuesto supone que hay un alto grado de consciencia y alfabetización mediática a la hora de exponerse a la televisión y, de todos es sabido, que la exposición suele estar más guiada por un uso ritualista (ver la televisión por el reloj) que instrumental (exposición guiada por la búsqueda de un objetivo concreto). Por otra parte, parece difícil minimizar el hecho de que la similitud con los personajes y situaciones no ejerza ninguna influencia; hoy se sabe que es un elemento de persuasión, como han puesto de manifiesto los estudios de psicología de la comunicación.

\subsection{Deslegitimación simbólica}

Banalización de la experiencia humana, culto a la superficialidad disfrazado de gloria efímera y equiparación de lo trivial con lo esencial en un mismo orden de importancia, forman parte del imaginario alimentado por la telerrealidad, en opinión de los expertos. Éste parece uno de los principales riesgos del hibridismo que caracteriza a los contenidos de telerrealidad. En un contexto en donde los méritos personales han sido sustituidos por la popularidad, las pantallas muestran personajes, desconocidos o famosos, que viven de la atención que les otorga el medio y esto puede estar contribuyendo a alimentar un modelo de éxito personal o proyecto de vida basado en el reconocimiento breve de la fama y la compensación económica de la celebridad. Trivialización, pérdida de referentes y lógica económica pueden estar incidiendo en la relación que la ciudadanía establece respecto a las cuestiones sociales, también en la producción de sujetos conformistas y adaptados, se ha dicho en este estudio.

\subsection{La revalorización de la cultura cotidiana}

Mostrar en la televisión las hazañas cotidianas de sujetos comunes obedece, en opinión de los expertos, más a la lógica económica que subyace, que a una auténtica revalorización de la cultura cotidiana en la que los límites entre lo público y lo privado se difuminan fácilmente. El acercamiento a las vidas de los otros se produjo, primero, en los programas de telerrealidad y ha continuado actualmente en las redes sociales (Tuenti, Facebook, Twitter). En la aldea global se ha producido un acercamiento a las vidas de otros sujetos que nos muestran sin ambages su alma en las pantallas: sus amores o fracasos sentimentales, sus alegrías cotidianas y sus dramas personales, del mismo modo que en el muro de algunas redes sociales se muestran las vacaciones, actividades y amigos de sus participantes, sin importar demasiado el grado de cercanía o relación que les une. En este momento, estamos quizá en proceso de redefinición de conceptos tradicionales como amigo, conocido, desconocido, etc. Primero, los programas de telerrealidad y crónica rosa acercaron al receptor la vida cotidiana de sujetos comunes desconocidos y personas famosas que pasaron a formar parte casi de nuestro círculo social, ahora, en una nueva vuelta de tuerca, podemos comunicarnos con ellos, aunque no los conozcamos y nunca vayamos a hacerlo, o seguirlos, conocer sus trayectorias e interactuar con ellos. 


\subsection{La ficcionalización del reality}

Se habla de formatos de telerrealidad porque en estos programas se parte de la realidad o se muestra la realidad, este es el valor que a veces se le ha dado: casi documental. Pero el discurso consensuado de los expertos muestra que se alejan mucho de ella, y que las estrategias de creatividad del medio y renovación de formatos quedan supeditadas a la lógica económica de conseguir un producto comunicativo de bajo coste y eficacia garantizada desde el punto de vista de la aceptación por parte de la audiencia. Los reality shows, en todas sus versiones (docu-game, talk-show, talent, coach, etc.) utilizan técnicas de guionización y reconstrucción que los acercan a la ficción, hasta el punto de que el resultado final es un espectáculo rentable para las cadenas y provechoso para sus protagonistas, en el que más que dar cuenta o mostrar la realidad, se la recrea y construye.

La televisión muestra cómo es el mundo, qué hacen las personas, cómo interactúan, cuáles son sus objetivos vitales y qué valores son importantes, pero lo hace desde un discurso sensacionalista que se relaciona, no ya tanto con lo que narra sino con la forma de narrarlo. El afán escópico de mostrar la realidad hasta en sus más íntimos detalles con el objetivo de llamar la atención e impactar a una audiencia que se aburre inmediatamente después de sorprenderse, ha producido una hiperrealidad televisiva que, a través de estrategias de fidelización y vinculación, gratifica y entretiene al espectador, pero que oculta más que lo que muestra.

\section{Referencias bibliográficas}

AIERBE, Ana; MEDRANO, Concepción; y MARTÍNEZ DE MORENTÍN, Juan Ignacio (2010): "La privacidad en programas televisivos: percepción de los adolescentes". Comunicar, 35, v. XVIII, 95-103.

BOUZA, Fermín (2000): “El mirón solitario”, en EL País, 29 de septiembre, sección Opinión: "Tribuna".

CÁCERES, María Dolores (2001): "La mediación comunicativa: El programa Gran Hermano". Zer, 11, 143-166.

CÁCERES, María Dolores (2002): “Operación Triunfo o el restablecimiento del orden social". Zer, 13, 11-27.

CÁCERES, María Dolores (2010): "El discurso de la televisión en la cultura del espectáculo: los procesos de mediación en los programas de la telerrealidad". Sphera Pública, 10, 207-222.

CAMPS, Victoria (2008): “¿Todo vale? Hacia una mirada ética en los medios de comunicación”. Comunicar, 31, v.XVI, 393-395.

CASTAÑARES, Wenceslao (2006): La televisión moralista: valores y sentimientos en el discurso televisivo. Madrid, Fragua.

CEBRIÁN, Mariano (1998): Información televisiva. Madrid, Síntesis.

CEBRIÁN, Mariano (2003): Estrategia multimedia de la televisión en "Operación Triunfo". Madrid, Ciencia 3. 
GAITÁN, Juan Antonio y PIÑUEL, José Luís (1998): Técnicas de investigación en comunicación social. Madrid, Síntesis.

GONZÁLEZ REQUENA, Jesús (2010): "La destrucción de la realidad en el espectáculo televisivo". Sphera Pública, 10, 17-41.

IMBERT, Gérard (2003): El zoo visual. De la televisión espectacular a la televisión especular. Barcelona, Gedisa.

IMBERT, Gérard (2008): El transformismo televisivo: postelevisión e imaginarios sociales. Madrid, Cátedra.

LACALLE, Charo (2000): "Mitologías cotidianas y pequeños rituales televisivos. Los talk shows". Anàlisi, 24, 79-92.

LACALLE, Charo (2001): El espectador televisivo: los programas de entretenimiento. Barcelona, Gedisa.

LAMUEDRA, María (2005): "Formatos híbridos y melodrama en televisión: El caso de Belén Esteban como heroína post-moderna. Estudio de recepción". Estudios sobre el mensaje periodístico, vol. 11, pp. 349-374. Madrid, Servicio de Publicaciones de la Universidad Complutense

LEÓN, Bienvenido (2009): Telerrealidad: el mundo detrás del cristal. Barcelona, Comunicación Social.

PALACIO, Manuel (2007): "Elementos para una genealogía del término "telebasura" en España". Trípodos, 21, 9-15.

SAMPEDRO, Víctor (2002): “Telebasura. Mctele y ETT”. Zer, 13, 29-45.

TORREGROSA, Juan Francisco (2010): "El discurso televisivo actual. Características y tendencias". Sphera Pública, 10, 195-206.

TAYLOR, Charles (2006): Imaginarios sociales modernos. Barcelona, Paidós. 